\title{
Hubungan Kebersihan Kepala dengan Pedikulosis Kapitis pada Komunitas Dinding di Pasar Bersehati Manado
}

\author{
Ayu Maharani, ${ }^{1}$ Herry E. J. Pandaleke, ${ }^{2}$ Nurdjannah J. Niode ${ }^{2}$
}

\author{
${ }^{1}$ Program Studi Pendidikan Dokter Fakultas Kedokteran Universitas Sam Ratulangi Manado \\ ${ }^{2}$ Bagian Ilmu Kesehatan Kulit dan Kelamin Fakultas Kedokteran Universitas Sam Ratulangi \\ RSUP Prof. Dr. R. D. Kandou Manado
}

Email: ayhumaharani1015@gmail.com

\begin{abstract}
Pediculosis capitis is an infection of the skin and hair caused by Pediculus humanus var capitis. This disease mainly attacks young children and spreads quickly in a crowded environment and poor hygiene condition. Transmission are mainly through direct contact headto-head or indirectly such as combs, hair accessories, pillows, veils, etc. Transmission is increasing with several factors inter alia age, sex, frequency of washing hair, sharing towels, beds as well as goods. This study was aimed to assess the relationship between head hygiene and pediculosis capitis among children fostered in Komunitas Dinding at Pasar Bersehati Manado. This was an analytical and observational study with a cross sectional design. Subjects consisted of 30 children, aged 5-15 years, and met the inclusion and exclusion criteria. Data were analyzed by using the chi-square test. The results showed that of 30 subjects, 18 children (60\%) had pediculosis capitis. The chi-square test showed that washing hair with shampoo per week $(\mathrm{p}=0.100)$, sharing towels $(\mathrm{p}=0.618)$, and sharing beds $(\mathrm{p}=0.177)$ did not have significant relationships with pediculosis capitis meanwhile sharing goods $(\mathrm{p}=0.002)$ had a significant relationship with pediculosis capitis. In conclusion, there was a relationship between sharing goods and pediculosis capitis among children fostered in Komunitas Dinding at Pasar Bersehati Manado.
\end{abstract}

Keywords: pediculosis capitis, children, scalp hygiene

\begin{abstract}
Abstrak: Pedikulosis kapitis merupakan infeksi kulit dan rambut kepala yang disebabkan oleh Pediculus humanus var capitis. Penyakit ini terutama menyerang anak-anak usia muda dan cepat meluas dalam lingkungan hidup yang padat dan kondisi higiene yang tidak baik. Penularan terutama secara kontak langsung melalui head-to-head maupun tidak langsung seperti sisir, aksesoris rambut, bantal, kerudung, dll. Penularan semakin meningkat dengan adanya faktor usia, jenis kelamin, frekuensi mencuci rambut, penggunaan handuk bersama, penggunaan tempat tidur bersama, dan penggunaan barang bersama. Penelitian ini bertujuan untuk mengetahui hubungan kebersihan kepala dengan pedikulosis kapitis pada anak-anak binaan Komunitas Dinding di Pasar Bersehati Manado. Jenis penelitian ialah analitik observasional dengan desain potong lintang. Subjek penelitian berjumlah 30 anak, berusia 5-15 tahun yang memenuhi kriteria inklusi dan eksklusi. Data penelitian diuji dengan uji chi-square. Hasil penelitian mendapatkan 18 anak (60\%) mengalami pedikulosis kapitis. Uji statistik menunjukkan bahwa mencuci rambut menggunakan sampo per minggu $(\mathrm{p}=0,100)$, penggunaan handuk bersama $(\mathrm{p}=0,618)$, penggunaan tempat tidur bersama $(\mathrm{p}=0,177)$ tidak memiliki hubungan bermakna dengan pedikulosis kapitis sedangkan penggunaan barang bersama $(\mathrm{p}=0,002)$ memiliki hubungan bermakna dengan pedikulosis kapitis. Simpulan penelitian ini ialah terdapat hubungan antara penggunaan barang bersama dengan pedikulosis kapitis pada anak-anak binaan Komunitas Dinding di Pasar Bersehati Manado.
\end{abstract}

Kata kunci: pedikulosis kapitis, anak, kebersihan kepala 


\section{PENDAHULUAN}

Pedikulosis ialah infeksi kulit/rambut pada manusia yang disebabkan oleh Pediculus (tergolong family Pediculidae). Selain menyerang manusia, penyakit ini juga menyerang binatang; oleh karena itu dibedakan Pediculus humanus dengan Pediculus animalis. Pediculus merupakan parasit obligat artinya harus menghisap darah manusia untuk dapat mempertahankan hidup. ${ }^{1}$

Secara morfologi, siklus hidupnya melalui stadium telur, larva, nimfa, dan dewasa. Telur diletakkan oleh betina dewasa dipangkal batang rambut terdekat kulit kepala. Telur membutuhkan waktu sekitar 1 minggu untuk menetas (kisaran 6-9 hari). Telur menetas untuk melepaskan nimfa. Nimfa terlihat seperti kutu kepala dewasa, dan menjadi dewasa 7 hari setelah menetas. Kutu dewasa kira-kira seukuran biji wijen, memiliki 6 kaki (masing-masing dengan cakar), dan berwarna kecoklatan sampai putih keabu-abuan. Kutu dewasa dapat hidup hingga 30 hari di atas kepala seseorang. Untuk hidup, kutu dewasa perlu makan darah beberapa kali sehari. ${ }^{1}$

Penyakit ini terutama menyerang anakanak usia muda dan cepat meluas dalam lingkungan hidup yang padat, misalnya di asrama dan panti asuhan. Tambahan pula dalam kondisi higiene yang tidak baik, misalnya jarang membersihan rambut atau rambut yang relatif sulit dibersihkan (rambut yang sangat panjang pada perempuan). Cara penularan biasanya melalui perantara (benda), seperti sisir, bantal, Kasur, dan topi. ${ }^{1-3}$

Prevalensi pedikulosis cukup tinggi di seluruh dunia. Di Amerika Serikat dilaporkan bahwa 6-12 juta orang terinfestasi setiap tahunnya dan diperkirakan sekitar 100 juta dolar diperlukan untuk pengobatannya. ${ }^{4}$ Sebagian besar pedikulosis kapitis terjadi pada anak-anak usia sekolah. Di negara maju seperti Nowegia kejadian pedikulosis mencapai 97.3\%. Di negara berkembang seperti Pakistan prevalensi pedikulosis kapitis pada anak usia sekolah sebesar $87 \%$, dan di Peru $87,6 \%$. Penyakit ini sering diabaikan terutama di negara yang terdapat prioritas kesehatan lain yang lebih serius, karena mortalitasnya yang rendah, namun penyakit ini telah menyebabkan morbiditas yang bermakna pada anak-anak sekolah di seluruh dunia. ${ }^{5}$ Penderita pedikulosis kapitis akan mengalami rasa gatal. Kelainan kulit akan bertambah berat bila digaruk dan dapat menyebabkan infeksi sekunder pada daerah kepala. $^{1,2}$ Oleh karena itu, diperlukan pengetahuan mengenai karakteristik dan kebiasaan individu yang berhubungan dengan terjadinya infestasi pedikulosis kapitis sehingga dapat mengurangi timbulnya dampak dari infestasi yang berat serta dapat mencegah infestasi secara keseluruhan. Dengan demikian dapat dilakukan usaha pencegahan agar terhindar dari infestasi penyakit tersebut.

Pedikulosis kapitis dapat ditemukan ditempat pengungsian, tuna wisma, dan perkampungan kumuh. Pedikulosis kapitis sering juga terjadi dan cepat meluas dalam lingkungan hidup yang padat, misalnya di asrama dan di panti asuhan. ${ }^{1}$

Kompleks Pasar Bersehati Manado yang terletak di Kelurahan Calaca, Kecamatan Wenang, Kota Manado, merupakan pasar tradisional yang padat. Tidak terdapat Sekolah Dasar (SD) di dekat situ. Jumlah anak usia sekolah sekitar 100 orang; 50 di antaranya setiap hari Sabtu mengikuti kegiatan belajar bersama Komunitas Dinding. Meski namanya komunitas dinding, sesungguhnya sekolah ini tidak berdinding. Terletak di lantai 3 salah satu bangunan Pasar Bersehati, kondisi ruangannya kurang bersih apalagi jika turun hujan. Di samping kelas-kelas itu, terlihat beberapa pedagang yang sedang menjemur cabai. Walaupun bau cabai cukup menyengat, namun kegiatan belajar tetap dilakukan.

Dinding Manado merupakan sebuah komunitas mengajar anak-anak pasar dan jalanan di Pasar Bersehati Manado. Dinding Manado tidak berorientasi menjadi organisasi, lembaga, atau yayasan tetapi ke sebuah gerakan yang bertujuan untuk menolong anak-anak yang berkekurangan agar tetap hidup layak dan dapat menjadi berkat bagi 
orang lain. Alasan peneliti melakukan penelitian pada anak binaan komunitas dinding di Pasar Bersehati Manado yaitu karena kondisi lingkungan yang begitu padat, kumuh, keadaan sosial ekonomi yang kurang mampu. Begitu juga kondisi lingkungan Pasar Bersehati dimana masih terdapat pedagang yang membuang sampah sembarangan, serta menjemur pakaian di sembarang tempat.

\section{METODE PENELITIAN}

Penelitian ini dilaksanakan di Pasar Bersehati Manado pada bulan Oktober 2019-November 2019. Jenis penelitian ini ialah analitik-observasional dengan metode penelitian kuantitatif dan desain potong lintang. Subyek penelitian yaitu anak-anak usia 5-15 tahun yang termasuk anak binaan komunitas dinding di Pasar Bersehati Manado dan memenuhi kriteria inklusi dan eksklusi. Penelitian ini dilakukan dengan menggunakan kuesioner untuk menilai kebersihan kepala dan pemeriksaan fisik langsung untuk menegakkan diagnosis pedikulosis kapitis.

Penelitian ini telah mendapat persetujuan dari Komisi Etik Penelitian Kesehatan RSUP Prof. Dr. R. D. Kandou Manado, dengan nomor keterangan layak etik yaitu No. 108/EC/KEPK-KANDOU/XII/2019.

\section{HASIL PENELITIAN}

Populasi penelitian ini ialah 76 anak binaan komunitas dinding di Pasar Bersehati Manado. Dari 76 anak tersebut didapatkan 30 anak yang memenuhi kriteria inklusi dan menjadi subyek penelitian. Berdasarkan usia didapatkan subyek berusia 5-11 tahun sebanyak 24 anak (80\%) dan yang berusia 12-16 tahun sebanyak 6 anak (20\%). Subyek dengan jenis kelamin lakilaki sebanyak 14 anak (47\%) dan jenis kelamin perempuan sebanyak 16 anak (53\%). Berdasarkan karakteristik infestasi Pediculus humanus var capitis didapatkan subyek yang positif sebanyak 18 anak $(60 \%)$ dan subyek yang negatif sebanyak 12 anak $(40 \%)$.

Tabel 1 memperlihatkan distribusi subyek berdasarkan mencuci rambut meng- gunakan sampo per minggu. Subyek terbanyak yaitu yang selalu menggunakan sampo (60\%), diikuti kadang-kadang menggunakan sampo (20\%), sering menggunakan sampo (17\%), dan jarang menggunakan sampo (3\%); tidak terdapat subyek yang tidak pernah menggunakan sampo.

Tabel 1. Distribusi subyek berdasarkan mencuci rambut menggunakan sampo

\begin{tabular}{lcc}
\hline $\begin{array}{c}\text { Menggunakan } \\
\text { sampo }\end{array}$ & Jumlah & $\begin{array}{c}\text { Persentase } \\
(\%)\end{array}$ \\
\hline Selalu & 18 & 66 \\
Sering & 5 & 17 \\
Kadang-kadang & 6 & 20 \\
Jarang & 1 & 3 \\
Tidak pernah & 0 & 0 \\
Total & 30 & 100 \\
\hline
\end{tabular}

Tabel 2 memperlihatkan distribusi subyek berdasarkan penggunaan handuk bersama. Subyek terbanyak yaitu yang selalu menggunakan handuk bersama (43\%), diikuti tidak pernah menggunakan handuk bersama (20\%), kadang-kadang menggunakan handuk bersama dan jarang menggunakan handuk bersama (masing-masing 17\%), serta sering menggunakan handuk bersama $(3 \%)$.

Tabel 2. Distribusi subyek berdasarkan penggunaan handuk bersama

\begin{tabular}{lcc}
\hline $\begin{array}{c}\text { Penggunaan } \\
\text { handuk bersama }\end{array}$ & Jumlah & $\begin{array}{c}\text { Persentase } \\
(\%)\end{array}$ \\
\hline Selalu & 13 & 43 \\
Sering & 1 & 3 \\
Kadang-kadang & 5 & 17 \\
Jarang & 5 & 17 \\
Tidak pernah & 6 & 20 \\
Total & 30 & 100 \\
\hline
\end{tabular}

Tabel 3 memperlihatkan distribusi subyek berdasarkan penggunaan tempat tidur bersama. Subyek terbanyak yaitu yang selalu menggunakan tempat tidur bersama (50\%), diikuti yang sering menggunakan tempat tidur bersama (17\%), kadang-kadang menggunakan tempat tidur bersama (13\%), serta jarang menggunakan tempat tidur 
bersama dan tidak pernah menggunakan tempat tidur bersama (masing-masing 10\%).

Tabel 4 memperlihatkan distribusi subyek berdasarkan penggunaan barang bersama yaitu sisir, topi, bando, kerudung, dan aksesoris rambut lainnya. Subyek terbanyak ialah yang sering menggunakan barang bersama (33\%), diikuti yang selalu menggunakan barang bersama (30\%), tidak pernah menggunakan barang bersama (20\%), kadang menggunakan barang bersama $(10 \%)$, dan jarang menggunakan barang bersama $(7 \%)$.

Tabel 5 memperlihatkan hasil uji chi square terhadap hubungan mencuci rambut menggunakan sampo per minggu dengan pedikulosis kapitis yang memperoleh nilai $p=0,100 \quad(p>0,05)$. Hal ini menunjukkan bahwa tidak terdapat hubungan bermakna antara keduanya.

Tabel 6 memperlihatkan hasil uji chi square terhadap hubungan penggunaan handuk bersama dengan pedikulosis kapitis yang mendapatkan nilai $\mathrm{p}=0,618(\mathrm{p}>0,05)$. Hal ini menunjukkan bahwa tidak terdapat hubungan bermakna antara keduanya.

Tabel 3. Distribusi subyek berdasarkan penggunaan tempat tidur bersama

\begin{tabular}{lcc}
\hline $\begin{array}{l}\text { Penggunaan tempat } \\
\text { tidur bersama }\end{array}$ & Jumlah & $\begin{array}{c}\text { Persentase } \\
(\%)\end{array}$ \\
\hline Selalu & 15 & 50 \\
Sering & 5 & 17 \\
Kadang-kadang & 4 & 13 \\
Jarang & 3 & 10 \\
Tidak pernah & 3 & 10 \\
Total & 30 & 100 \\
\hline
\end{tabular}

Tabel 4. Distribusi subyek berdasarkan penggunaan barang bersama

\begin{tabular}{lcc}
\hline $\begin{array}{l}\text { Penggunaan } \\
\text { barang bersama }\end{array}$ & Jumlah & $\begin{array}{c}\text { Persentase } \\
(\boldsymbol{\%})\end{array}$ \\
\hline Selalu & 9 & 30 \\
Sering & 10 & 33 \\
Kadang-kadang & 3 & 10 \\
Jarang & 2 & 7 \\
Tidak pernah & 6 & 20 \\
Total & 30 & 100 \\
\hline
\end{tabular}

Tabel 5. Hubungan mencuci rambut menggunakan sampo per minggu dengan pedikulosis kapitis

\begin{tabular}{lccccccc}
\hline \multirow{2}{*}{$\begin{array}{c}\text { Mencuci rambut menggunakan } \\
\text { sampo per minggu }\end{array}$} & \multicolumn{7}{c}{ Pedikulosis kapitis } \\
& N & $\%$ & N & $\%$ & N & $\%$ & \\
\hline Selalu & 9 & 50 & 9 & 50 & 18 & 100 & \\
Sering & 2 & 40 & 3 & 60 & 5 & 100 & \\
Kadang-kadang & 6 & 100 & 0 & 0 & 6 & 100 & 0,100 \\
Jarang & 1 & 100 & 0 & 0 & 1 & 100 & \\
Total & 18 & & 12 & & 30 & 100 & \\
\hline
\end{tabular}

Tabel 6. Hubungan penggunaan handuk bersama dengan pedikulosis kapitis

\begin{tabular}{llllllll}
\hline \multicolumn{1}{c}{$\begin{array}{c}\text { Penggunaan } \\
\text { handuk bersama }\end{array}$} & \multicolumn{2}{c}{ Pedikulosis kapitis } & \multicolumn{2}{c}{ Nilai $\mathrm{p}$} \\
& $\mathrm{N}$ & $\%$ & $\mathrm{~N}$ & $\%$ & $\mathrm{~N}$ & $\%$ & \\
\hline Selalu & 7 & 53,8 & 6 & 46,2 & 13 & 100 & \\
Sering & 1 & 100 & 0 & 0 & 1 & 100 & \\
Kadang-kadang & 4 & 80 & 1 & 20 & 5 & 100 & 0,618 \\
Jarang & 2 & 40 & 3 & 60 & 5 & 100 & \\
Tidak pernah & 4 & 66,7 & 2 & 33,3 & 6 & 100 & \\
Total & 18 & 100 & 12 & 100 & 30 & 100 & \\
\hline
\end{tabular}


Tabel 7. Hubungan penggunaan tempat tidur bersama dengan pedikulosis kapitis

\begin{tabular}{|c|c|c|c|c|c|c|c|}
\hline \multirow{3}{*}{$\begin{array}{l}\text { Penggunaan tempat } \\
\text { tidur bersama }\end{array}$} & \multicolumn{6}{|c|}{ Pedikulosis kapitis } & \multirow{3}{*}{ Nilai $p$} \\
\hline & \multirow[b]{2}{*}{$\mathrm{N}$} & \multicolumn{2}{|c|}{$(+)$} & \multicolumn{2}{|c|}{$(-)$} & \multirow{2}{*}{$\begin{array}{c}\text { Total } \\
\%\end{array}$} & \\
\hline & & $\%$ & $\mathrm{~N}$ & $\%$ & $\mathrm{~N}$ & & \\
\hline Selalu & 9 & 90 & 6 & 40 & 15 & 100 & \\
\hline Sering & 5 & 100 & 0 & 0 & 5 & 100 & \\
\hline Kadang-kadang & 1 & 25 & 3 & 75 & 4 & 100 & 0,177 \\
\hline Jarang & 2 & 66,7 & 1 & 33,3 & 3 & 100 & \\
\hline Tidak pernah & 1 & 33,3 & 2 & 66,7 & 3 & 100 & \\
\hline Total & 18 & 100 & 12 & 100 & 30 & 100 & \\
\hline
\end{tabular}

Tabel 8. Hubungan penggunaan barang bersama dengan pedikulosis kapitis

\begin{tabular}{lclllllll}
\hline \multirow{2}{*}{ Penggunaan barang bersama } & \multicolumn{7}{c}{ Pedikulosis kapitis } \\
& \multicolumn{2}{c}{$(+)$} & \multicolumn{1}{c}{$(-)$} & \multicolumn{2}{c}{ Total } & Nilai $\mathrm{p}$ \\
& $\mathrm{N}$ & $\%$ & $\mathrm{~N}$ & $\%$ & $\mathrm{~N}$ & $\%$ & \\
\hline Selalu & 7 & 77,8 & 2 & 22,2 & 9 & 100 & \\
Sering & 9 & 90 & 1 & 10 & 10 & 100 & \\
Kadang-kadang & 2 & 66,7 & 1 & 33,3 & 3 & 100 & 0,002 \\
Jarang & 0 & 0 & 2 & 100 & 2 & 100 & \\
tidak pernah & 0 & 0 & 6 & 100 & 6 & 100 & \\
Total & 18 & 100 & 12 & 100 & 30 & 100 & \\
\hline
\end{tabular}

Tabel 7 memperlihatkan hasil uji chi square terhadap hubungan penggunaan tempat tidur bersama dengan pedikulosis kapitis yang mendapatkan nilai $\mathrm{p}=0,177$ ( $\mathrm{p}$ $0,05)$. Hal ini menunjukkan tidak terdapat hubungan bermakna antara keduanya.

Tabel 8 memperlihatkan hasil uji chi square terhadap hubungan penggunaan barang bersama dengan pedikulosis kapitis yang mendapatkan nilai $\mathrm{p}=0,002(\mathrm{p}<0,05)$; hal ini menunjukkan terdapatnya hubungan bermakna antara keduanya.

\section{BAHASAN}

Dari hasil pemeriksaan secara langsung untuk menegakkan diagnosis pedikulosis kapitis terhadap 30 anak binaan Komunitas Dinding di Pasar Bersehati Manado didapatkan 18 anak (60\%) yang positif pedikulosis kapitis dan 12 anak (40\%) yang negatif pedikulosis kapitis. Hal ini menunjukkan bahwa pedikulosis kapitis masih menjadi masalah kesehatan pada anak binaan Komunitas Dinding di Pasar Bersehati Manado.
Pada penelitian di Pondok Pesantren Ma'hadul Muta'alimin Kecamatan Widodaren didapatkan 29 anak (58\%) yang positif pedikulosis kapitis dan 21 anak (42\%) yang negatif pedikulosis kapitis, ${ }^{6}$ sedangkan penelitian di Pondok Pesantren Miftahul Ulum Kalisat Jember mendapatkan 214 orang santri $(74,6 \%)$ yang positif pedikulosis kapitis dan 73 orang lainnya negatif pedikulosis kapitis. ${ }^{5}$

Pada penelitian ini didapatkan dari 30 subjek penelitian terdapat 24 anak yang termasuk dalam kelompok usia 5-11 tahun dan 6 anak yang termasuk dalam kelompok usia 12-16 tahun. Secara umum anak binaan Komunitas Dinding ini berada diusia 3-18 tahun dan didominasi oleh kelompok usia 5 -11 tahun. Dari total 18 subyek yang positif pedikulosis kapitis, 16 di antaranya berusia 5-11 tahun dan 2 di antaranya berusia 12-16 tahun. Hal ini sesuai dengan teori yang menyatakan bahwa pedikulosis kapitis lebih banyak menginfestasi anak-anak karena mereka kurang dapat menjaga kebersihan 
kulit kepala. Kelompok anak usia sekolah memiliki aktivitas lebih banyak bersama dengan teman sebaya, sehingga penularannya lebih mudah terjadi. ${ }^{7}$

Pada penelitian ini, dari total 30 subyek, paling banyak didapatkan jenis kelamin perempuan yaitu sebanyak 16 anak (53\%) sedangkan pada anak laki-laki sebanyak 14 anak (47\%). Berdasarkan data yang diperoleh, populasi anak binaan Komunitas Dinding di Pasar Bersehati Manado menunjukkan bahwa lebih dominan jenis kelamin perempuan dibandingkan dengan laki-laki. Hasil penelitian ini memperlihatkan bahwa dari total 30 subyek, terdapat 18 anak yang postif pedikulosis kapitis, 13 di antaranya berjenis kelamin perempuan dan 5 diantaranya berjenis kelamin laki-laki. Hal ini juga didukung oleh penelitian pada murid SDN 019 Tebing Tinggi Okura di Kecamatan Rumbai Pesisir Pekanbaru yang melaporkan dari total 135 responden, terdapat 53 anak yang mengalami pedikulosis kapitis; 47 anak di antaranya berjenis kelamin perempuan dan 6 di antaranya berjenis kelamin laki-laki. ${ }^{8}$

Anak perempuan memilki kebiasaan saling menggunakan sisir/aksesoris rambut bersama dengan teman, saudara, dan keluarganya. Sebagai contoh, kerudung, bando, topi, handuk, dll. Selain itu, dapat disebabkan karena umumnya anak perempuan berambut lebih panjang daripada anak lakilaki, sehingga membutuhkan perawatan yang baik. Anak perempuan memiliki perilaku kebiasaan close contact yang cukup lama pada saat bermain, tidur bersama. Berbeda halnya dengan anak laki-laki yang jarang terjadi close contact; mungkin hanya aktivitas tertentu atau memiliki keluarga/ saudara yang mengalami pedikulosis kapitis.

Hasil penelitian mendapatkan 18 subyek yang positif pedikulosis kapitis. Kategori yang digunakan oleh peneliti yaitu selalu, sering, kadang-kadang, jarang, dan tidak pernah. Dari lima kategori tersebut, jumlah subyek yang selalu mencuci rambut menggunakan sampo per minggu sebanyak 9 anak, yang sering mencuci rambut menggunakan sampo per minggu sebanyak 2 anak, kadang-kadang mencuci rambut menggunakan sampo per minggu sebanyak 6 anak, dan jarang mencuci rambut menggunakan sampo per minggu sebanyak 1 anak (Tabel 5). Menurut Nurjannah, ${ }^{9}$ personal hygiene rambut merupakan upaya seseorang menjaga kebersihan dan kesehatan untuk mencegah munculnya gangguan maupun penyakit pada rambut baik untuk dirinya maupun orang lain. Salah satu contoh yaitu dengan mencuci rambut minimal 3 kali seminggu dengan menggunakan sampo.

Hasil uji chi-square mendapatkan nilai $\mathrm{p}=0,100$ yang menunjukkan tidak terdapat hubungan bermakna antara mencuci rambut menggunakan sampo per minggu dengan pedikulosis kapitis. Penelitian yang dilaksanakan oleh AlBashtawy dan Hasna ${ }^{10}$ menyatakan bahwa terdapat hubungan antara frekuensi cuci rambut dengan dengan kejadian Pedikulosis kapitis $(\mathrm{p}=0,0001)$, yang berarti semakin sering mencuci rambut maka akan mengurangi risiko terjadinya pedikulosis kapitis. Berbeda dengan hasil penelitian ini yang menunjukkan bahwa subyek yang rajin mencuci rambut menggunakan sampo masih mengalami pedikulosis kapitis. Hal ini dikarenakan mencuci rambut menggunakan sampo saja tidak dapat membunuh Pediculus humanus var. capitis, selesai mencuci rambut seharusnya diikuti dengan menyisir rambut menggunakan sisir serit. ${ }^{5}$ Melihat kondisi lingkungan Pasar Bersehati Manado, faktor infrastuktur khususnya fasilitas MCK dan air bersih dapat berdampak pada kualitas higiene yang kurang khususnya perilaku dalam mencuci rambut. ${ }^{11}$

Pada 18 subyek penelitian yang positif pedikulosis kapitis, kategori yang digunakan oleh peneliti yaitu selalu, sering, kadang-kadang, jarang, dan tidak pernah. Dari lima kategori tersebut, 7 anak selalu menggunakan handuk bersama, 1 anak sering menggunakan handuk bersama, 4 anak kadang-kadang menggunakan handuk bersama, 2 anak jarang menggunakan handuk bersama, dan 4 anak tidak pernah menggunakan handuk bersama (Tabel 6). Menggunakan handuk secara bersama merupakan salah satu faktor yang bisa 
menyebabkan terjadinya pedikulosis kapitis bila terdapat keluarga/saudara yang mengalami penyakit ini.

Hasil uji chi-square mendapatkan nilai $\mathrm{p}=0,618$ yang menunjukkan tidak terdapat hubungan bermakna antara penggunaan handuk bersama dengan pedikulosis kapitis. Hal ini sejalan dengan penelitian yang dilakukan oleh Rumampuk ${ }^{7}$ terhadap penghuni 10 panti asuhan di Sulawesi Utara (2014).

Pada 18 subyek yang postif pedikulosis kapitis, kategori yang digunakan oleh peneliti yaitu selalu, sering, kadang-kadang, jarang, dan tidak pernah. Dari lima kategori tersebut, 9 anak selalu menggunakan tempat tidur bersama, 5 anak sering menggunakan tempat tidur bersama, 1 anak kadangkadang menggunakan tempat tidur bersama, 2 anak jarang menggunakan tempat tidur bersama, dan 1 anak tidak pernah menggunakan tempat tidur bersama (Tabel 7). Hasil ini menunjukkan penggunaan tempat tidur bersama dapat memengaruhi terjadinya penyakit pedikulosis kapitis. Hal ini disebabkan karena berbagi bantal atau tempat tidur dapat memfasilitasi kutu rambut untuk bertransmisi secara langsung melalui kontak antar kepala yang intens terutama jika salah seorang teman tidur tersebut menderita pedikulosis kapitis. ${ }^{12}$

Hasil uji chi-square mendapatkan nilai $\mathrm{p}=0,177$ yang menunjukkan tidak terdapat hubungan bermakna antara penggunaan tempat tidur bersama dengan pedikulosis kapitis. Hal ini sejalan dengan penelitian yang dilakukan oleh Saraswati ${ }^{11}$ terhadap anak pedagang di Pasar Bersehati Kota Manado tahun 2017 tetapi berbeda dengan hasil penelitian yang dilakukan oleh Rumampuk $^{7}$ terhadap penghuni 10 panti asuhan di Sulawesi Utara (2014). Pada usia anak, mereka cenderung belum mandiri contohnya yaitu masih perlu ditemani keluarga, sehingga anak yang awalnya tidak mengalami pedikulosis kapitis dapat tertular jika tidur bersama dengan orang yang menderita pedikulosis kapitis sehingga transmisi penularan kutu melalui penggunaan tempat tidur bersama memiliki kemungkinan dapat terjadi namun sangat kecil.
Pada 18 subyek yang positif pedikulosis kapitis, kategori yang digunakan oleh peneliti yaitu selalu, sering, kadang-kadang, jarang, dan tidak pernah. Dari lima kategori tersebut, 7 anak selalu menggunakan barang bersama, 9 anak sering menggunakan barang bersama, dan 2 anak kadang-kadang menggunakan barang bersama (Tabel 8). Hasil penelitian ini menunjukkan bahwa subyek yang saling bertukar sisir ataupun aksesoris rambut lainnya menyebabkan positif pedikulosis kapitis. Hal ini selaras dengan penelitian yang dilakukan oleh Rumampuk $^{7}$ yang melaporkan terdapatnya responden yang positif pedikulosis kapitis dengan menggunakan sisir bersama sebanyak 96 orang.

Hasil uji chi-square mendapatkan nilai $\mathrm{p}=0,002$ yang menunjukkan terdapatnya hubungan bermakna antara penggunaan barang bersama dengan pedikulosis kapitis. Penelitian oleh Restiana ${ }^{13}$ terhadap penghuni asrama menunjukkan bahwa terdaapt hubungan antara penggunaan sisir secara bergantian dengan kejadian pedikulosis kapitis $(p=0,019)$. Salah satu faktor penularan kutu rambut yaitu dengan kontak tidak langsung (melalui benda) yang dipakai bersama yang telah terkontaminasi kutu rambut (kutu dewasa, nimfa, ataupun telur).

Menggunakan sisir atau aksesoris rambut bersama (pada keadaan menggunakan sisir secara bersamaan) akan membuat telur bahkan kutu dewasa menempel pada sisir sehingga akan tertular. Demikian pula halnya dengan aksesoris rambut seperti kerudung, bando, dan pita. Berdasarkan teori, penularan pedikulosis kapitis terutama terjadi melalui kontak langsung yang erat dari kepala ke kepala. Selain itu dapat terjadi pada kontak tidak langsung dengan fomite yang telah terinfestasi seperti sisir, sikat, alat pengering rambut, aksesoris rambut, bantal, sarung bantal, topi maupun penutup kepala lainnya. ${ }^{14}$

Suatu kondisi tempat tinggal yang penuh sesak contohnya tempat tinggal yang tidak sesuai atau seimbang dengan jumlah anggota keluarga menyebabkan penggunaan barang-barang seperti sisir atau aksesoris rambut bersama sering terjadi sehingga 
kerap menjadi jalur transmisi pasif bagi Pediculus humanus var. capitis. Berdasarkan pengamatan peneliti terhadap aktivitas harian subyek penelitian, didapatkan fakta bahwa menggunakan/meminjam barang menjadi suatu kebiasaan baik pakaian ataupun sisir maupun aksesoris rambut seperti bando dan jepit rambut yang mendukung terjadinya penularan tidak langsung.

\section{SIMPULAN}

Pada anak binaan Komunitas Dinding di Pasar Bersehati Manado didapatkan sebagian besar mengalami pedikulosis kapitis. Tidak terdapat hubungan antara mencuci rambut menggunakan sampo per minggu, penggunaan handuk bersama, dan penggunaan tempat tidur bersama dengan kejadian pedikulosis kapitis tetapi terdapat hubungan bermakna antara pengunaan barang bersama dengan kejadian pedikulosis kapitis.

Bagi pengelola Pasar Bersehati Manado disarankan agar lebih memperhatikan kebersihan di lingkungan pasar yang di dalamnya terdapat anak-anak binaan Komunitas Dinding yang perlu mendapat banyak perhatian.

Bagi orang tua subyek agar lebih memperhatikan kebersihan diri anak-anak dan menerapkan cara-cara menjaga kebesihan kepala/rambut untuk mengurangi angka kejadian pedikulosis kapitis.

Bagi peneliti lanjut, agar dapat menambah variabel dan jumlah sampel penelitian agar hasil penelitian dapat lebih akurat.

\section{Konflik Kepentingan}

Penulis menyatakan tidak terdapat konflik kepentingan dalam studi ini.

\section{DAFTAR PUSTAKA}

1. Handoko RP. Pedikulosis. In: Djuanda A, Hamzah M, Aisah S, editors. Ilmu Penyakit Kulit dan Kelamin (6th ed). Jakarta: Fakultas Kedokteran Universitas Indonesia, 2010; p. 119-20.

2. Wolff K, Johnson RA, Saavedra AP, editors. Fitzpatrick's Color Atlas and Synopsis of Clinical Dermatology (7th ed). New York: McGraw-Hill, 2013; p. 704-5.

3. Chowdhury MMU, Katugampola RP, Finlay AY, editors. Dermatology at a Glance. New Jersey: John Wiley \& Sons, 2013; p. 48.

4. Setyoasih A, Suryani D. Hubungan antara pengetahuan, personal hygiene, dan infestasi Pediculus humanus var. capitis pada Santriwati Muhammadiyah Boarding School Prambanan Sleman Yogyakarta. Jurnal Kedokteran dan Kesehatan. 2016;12:190-201.

5. Lukman N, Armiyanti Y, Agustina D. Hubungan faktor-faktor risiko Pediculosis capitis terhadap kejadiannya pada santri di Pondok Pesantren Miftahul Ulum Kabupaten Jember. Fakultas Kedokteran Universitas Jember. 2018

6. Tri MF. Hubungan personal hygiene dan tingkat pengetahuan dengan kejadian Pediculosis Capitis di Pondok Pesantren Ma'Hadul Muta'Alimin di Kecamatan Widodaren Kabupaten Ngawi [Doctoral dissertation]. Madiun: Stikes Bhakti Husada Mulia; 2018.

7. Rumampuk MV. Peranan kebersihan kulit kepala dan rambut dalam penanggulangan epidemiologi Pediculus Humanus Capitis. Jurnal Ners. 2014;9(1):3542.

8. Zulinda A, Yolazenia Y, Zahtamal Z. Faktorfaktor yang mempengaruhi kejadian pedikulosis kapitis pada murid kelas III, IV, V dan VI SDN 019 Tebing Tinggi Okura Kecamatan Rumbai Pesisir Pekanbaru. Jurnal Ilmu Kedokteran. 2017;4(1):65-9.

9. Nurjannah A. Personal hygiene siswa Sekolah Dasar Negeri Jatinangor. Students eJournal. 2012;1(1):31.

10. Al Bashtawy M, Hasna F. Pediculosis capitis among primary-school children in Mafraq Governorate, Jordan. Eastern Mediterranean Health Journal. 2012; 18(1):43.

11. Saraswati PC. Faktor risiko yang berhubungan dengan kejadian infestasi Pediculus humanus capitis pada anak pedagang di Pasar Bersehati Kota Manado [Skripsi]. Manado: Universitas Sam Ratulangi; 2017.

12. Rahman ZA. Faktor-faktor yang berhubungan dengan kejadian Pediculosis capitis pada santri Pesantren Rhodlotul Quran Semarang [Skripsi]. Semarang: Universitas Diponegoro; 2014

13. Restiana R. Hubungan berbagai faktor risiko terhadap angka kejadian pedikulosis kapitis di asrama [Tesis]. Yogyakarta, 
Universitas Muhammadiyah Yogyakarta; 2010.

14. Niode NJ, Kapantow MG. Gigitan serangga dan infestasi parasit. Manado: Unsrat Press, 2019. 